Int. J. Electrochem. Sci., 15 (2020) 5193 - 5207

International Journal of

ELECTROCHEMICAL

SCIENCE

www.electrochemsci.org

\title{
Comparative Study on the Corrosion Behaviours of High-Silicon Chromium Iron and Q235 Steel in a Soil Solution
}

\author{
Kechen $L v^{1}$, Song $X u^{2}$, Lanlan Liu ${ }^{3}$, Xinming Wang ${ }^{1}$, Cong $\mathrm{Li}^{1}$, Tangqing $W u^{1,}{ }^{*}$, Fucheng Yin ${ }^{1}$ \\ ${ }^{1}$ Key Laboratory of Materials Design and Preparation Technology of Hunan Province, School of \\ Materials Science and Engineering, Xiangtan University, Xiangtan 411105, China; \\ ${ }^{2}$ Electric Power Research Institute, State Grid Hunan Electric Power Co. Ltd, Changsha 410007, \\ China; \\ ${ }^{3}$ Maintenance Company, State Grid Hunan Electric Power Co. Ltd, Changsha 410100, China \\ *E-mail: tqwu@xtu.edu.cn
}

doi: $10.20964 / 2020.06 .16$

Received: 11 November 2019 / Accepted: 8 January 2020 / Published: 10 May 2020

High-silicon chromium iron (HSCI) has been applied in grounding grids for some DC converter stations. However, there is a lack of experimental studies on its corrosion behaviour in a soil environment. In this paper, the corrosion behaviours of HSCI and Q235 steel in a soil solution were studied by optical microscopy, electrochemical measurements, SEM/EDS and 3D ultra-depth microscopy. The results show that the anode and cathode polarization branches of HSCI and Q235 steel are mainly dominated by electrochemical polarization. The corrosion resistance of HSCI is much better than that of Q235 steel in the soil solution. The high content of $\mathrm{Cr}$ and $\mathrm{Si}$ is beneficial for the high corrosion resistance of HSCI; however, the original defects in HSCI promote its corrosion process. Therefore, the reduction of number of the original defects may be conducive to further improving the corrosion resistance of HSCI.

Keywords: High-silicon chromium iron (HSCI); Q235 steel; electrochemical impedance spectroscopy (EIS); polarization curve

\section{$\underline{\text { FULL TEXT }}$}

(C) 2020 The Authors. Published by ESG (www.electrochemsci.org). This article is an open access article distributed under the terms and conditions of the Creative Commons Attribution license (http://creativecommons.org/licenses/by/4.0/). 